EL PBNSAMIENTO DE MAIMONIDES

Fernando Valenzuela Grazo Departamento de Filosofia 


\section{EL PENSAMIEnTO de maImonides}

\section{Fernando Valenzuela $\mathbf{E}$.}

La evolución histórica de la comunidad judia, sus manifestaciones espirituales y sociales, representan una consolidación del pensamiento judio y un estilo de vida, que se expresan en actitudes fundamentales.

Se ha observado que hay un modo de ser judio que tiene caracteristicas propias, el que se perfila a través de las épocas con rasgos permanentes y que "llega hasta nuestros dias con una individualidad perfectamente identificable.

Se visualiza en la cultura de Israel la cristalización de una experiencia histórica que, en algunos de sus aspectos, principalmente politicos y culturales, debe considerarse simplemente como el resultado de una decantación de la vivencia histórica, de la profecia y de la fe, en la proyección historica de la vida de ese puebio.

El fenómeno se presenta con valores de permanencla en las variadas fases de la evolución cultural; tiene una manera de ser fiel a una visión y plantea una modalidad de propuesta que se integra en la acción, a partir de una ldea principal basada en la enseñanza de las escrituras.

El proceso se vincula en sú origen a una suerte de universalización del pensamiento judio que se inicia en el periodo de la dispersión y que reconoce en Maimónides a uno de sus grandes sistematizadores. 
La situación de la religión vinculada a esta experiencia histórica puede ser examinada desde varios puntos de vista. Interesa por el momento el estudio de estos antecedentes en la coyuntura de historia y profecia, en relación con el pensamiento de Maimónides, uno de los hitos significativos del gran renacimiento medieval de los siglos XII y XIII.

Parece evidente que, a partir de una problemática de origen religioso, se pueda descubrir de modo muy auténtico una de las fuentes más importantes de la cultura judia, intrinseca a la formación del pensamiento occidental. La interpretación de la experiencia vernácula del pueblo elegido, se presenta en este aspecto, como un proceso de universalización de la religión, forma de enseñanza que trae a la vida practica la sabidurla que contiene la profecia.

El ascenso de la experiencia singular, en la solución de los problemas que affectan a los judios, muestra con evidencía la generalización de este pensamiento a consecuencia de lo cual se plantea en la ldea de un logos, un lenguaje, una hermenéutica, etc. Con ello se trata de compatibilizar la experiencia particular en el trazado de una cultura general, forma de interpretación, en suma, de lo vernáculo y hermético de una comunidad historica en los baremos del pensamiento universal. La cultura judia ha logrado este resultado gracias al fenómeno de cristalización, no exento de una motivación fundamental, lograda en parte gracias a la influencia del pensamiento de Maimonides.

Este pensador representa uno de los momentos más decisivos del desarrollo espiritual judio. Nacido en Cordoba, España, en 1135, emigro de su suelo natal, instalandose primero 
en Fez en el norte de Africa en 1160, viviendo después en Palestina hacia 1165. Posteriormente, se establecio en Egipto, en la localidad de fostat, cerca de El Cairo. Fue médico de la corte de Saladino en Alejandria, comentarista del Talmud y de la Mishná y príncipal Eilosofo judio de la Edad Media.

Moses ben Maimon, Moise ben Maimon o simplemente Moses Maimonides, 1 lamado por los árabes Abu Imram Musá Ibn Maimon Abdallah o el 'Rabbi Moise' como lo recuerda Santo Tomás. Su principal obra filosofica es 'La Guia para los Extraviados' que ha sido traducida a varios idiomas. Al ingles bajo el titulo 'Guide for the perplexed' $y$ al francés como 'Guide des Indecs'. Su $:$ titulo en hebreo es 'More Nebukin' $y$ en árabe 'Dalalat alhairin'.

Esta obra es una suma teológica escolastica judia gue contiene el pensamiento filosofico de su tiempo. De inspiración neoplatónica, recibe la influencia de Aristóteles y está escrita en el espiritu del aristotelismo. Maimónides, junto con Averroes y Santo Tomás, es uno de los grandes intérpretes del pensamiento del Estagirita. La historia de la filosofia recuerda que durante ese periodo se establecieron las tres grandes lecturas del aristotelismo universal, cada una de las cuales pertenece a estos pensadores. La interpretación de Maimónides va a gozar de una larga vigencia en el pensamiento israelita.

El tratado se encuentra dividido en tres partes. En la primera plantea los problemas de antropomorfismo biblico, los atributos divinos y una exposición y critica de las enseñanzas del Kalam. La segunda, aborda las pruebas de la existencia de Dios, examen de las teorias de materia $y$ forma, creatio de novo 
y una exposición de la profecia. La tercera examina la cuestion de Dios y el mundo, incluyendo el problema de la providencia, el mal, la preciencia, la libertad de la voluntad, además de la teleologia y racionalidad de los preceptos de la Torá.

El papel de Maimónides ha sido de vital importancia por la influencia que ha ejercido en su época $y$ en los tiempos pósteriores. Sus ideas se adaptan al modo de ser judio, encuentran que vinculan a este espiritu que el trata de conducir $y$ orlentar en las generaciones. Esta vida religiosa fundada en el pensamiento profético tiene un dominio amplio, sin parangón en el mundo occidental, en el sentido de dar cabal cumplimiento a la palabra de los profetas.

La tesis que postula una experiencia de cristalización de la conciencla religiosa, responde a una consolidacionsui generis de la unidad vivencial del pueblo judio. Ella se inicia en un pasado original y fundante, de carácter mitico-religioso, $y$ después, de: modo contínuado ratifica una tradición de respeto $y$ obediencia al texto biblico, se hace universal en el exilio y se consagra en nuestra epoca en una experiencia politica de motivación religlosa, cuya es la surgencia del sistema actual existente en Israel.

Con: seguridad, esa conciencia se extendera al futuro pues se trata de una experiencia que nos habla de una posibilidad de realización ontologica de lo humano ý de una forma de vida que se encauza hacia valores permanentes dentro del proceso mundial: El pasado se hace contemporáneo,' se cristaliza en logros actuales gue se proyectan hacia el futuro cuyos haces de Influencia buscan una expresión, una perfección que trata de 
realizarse en lo histórico. El movimiento de la fe se presenta como la culminación de este proceso, digamos que es el resultado de una unidad original, cuya estructura reconoce en su base un concepto de fidelidad al vinculo religioso, una suerte de nexo de afianzamiento ético y politico que revela el ser propio de una creencia religiosa.

El pensamiento de Maimónides se vincula a este proceso y cobra importancia en la época presente. En otro tiempo, el abordo problemas filosoficos.y doctrinales cuyas soluciones conservan todavla una frescura $y$ actualidad renovadas, que sirve de gula permanente al hombre moderno.

Lo apreciamos, en efecto, en el apoyo de su filosofía para desestimar los conceptos negativos que surgian en esa época (y en la actualidad), como el nihilismo, el irracionalismo, el escepticismo, etc. La filosofia contemporanea ha puesto en evidencia estos fenomenos, formas de negativismo metafisico que configuran una consecuencia, un frente de reacción en contra de algunas de las soluciones que ofrece el intelectualismo filosofico; semejante situación conduce a un cambio profundo de los. valores individuales $y$ sociales. En todo intelectualismo filosofico ronda impredecible un nihilismo de base, que trata de ganar sus ventajas por la falta de sentido que a trechos exhibe la visión de aquel. Una filosofia de la voluntad, del hacer, logra sobrepujar esta tendencia, pero también queda a medio camino porque su visión casi siempre resulta limitada, antropomorfica $y$ condicionada a las posibilidades contingentes del hombre. En Maimónides incide una problematica religiosa que avanza hacia una perspectiva de fundamento en Dios, que supera a las partes contendientes, otorgando a cada una de ellas un papel de impor- 
tancia en el todo pero guardando para si la clave que ordena la totalidad del sistema bajo una hermeneutica que le otorga sentido a la palabra divina. Frente a la conclencla fundada en el poder de la razón o de la voluntad, procede la tradicional autoridad de Dios. El mundo suprasensible se enfrenta al mundo historico, los fines de un ideal de felicidad terrena se transforman en la aspiración a lograr los bienes ultra terrenos de la bienaventuranza divina, el concepto de religión se opone al de civilización, la autosuficiencia del quehacer humano se reemplaza por la creación divina. Es cierto que en Maimónides estas preposiciones tienen un alcance que, como veremos más delante, se compatibilizan con una posibilidad de perfeccionamiento normativo de la ley dentro de una interpretación que acoge de modo pleno la verdad religiosa.

Este problema de perfeccionar la ley, que Maimónides formula con toda claridad en sus escritos, es que el que más interesa en su proyección futura. Plantea la controversia de una metafisica intelectualista frente a otra de tipo voluntarista, el pensador no asume ninguna de ellas de modo absoluto; 10 decisivo de su postulación radica en que introduce una forma de conciliación de ambas posibilidades que consiste en proyectar esas ideas a un sistema de vida practica orientada por la sabidurla de las enseñanzas que provienen de la profecia. De la interpretación de los textos sagrados surge una concepción del mundo, de lo social y politico que él relaciona con el pensamiento mundano, sacando de alli las conclusiones que contribuyen a ordenar la vida del pueblo judio. Este es el problema que trata de resolver Maimónides en plena Edad Media (Siglo XII) y los criterios que usa son actuales, claves que permiten retrotraer las tendencias de la filosofia contemporanea an antece- 
dente original y remoto, una suerte de señal anticipada de una conciencia filosofica excepcional que se mueve en una provisión actual.

El pensamiento de Maimónides, siendo de conciliación, es contrario sin embargo a clertas relativizaciones. El adhiere a una concepción del ser cuya manifestación superior se encuentra en lo suprasensible, juicio absoluto que ordena al hombre a poner su destino en las manos de Dios. Pero esto no indica que su filosofía separe suficlentemente los problemas del ser de los del valor o la justificación. Eso sería colocarlo en el analisis de la situación actual, propia de una teoría de los valores planteada al modo moderno. Su orientación es más bien aclaratoria en su inicio de aspectos que tendrán enorme importancia en la situación vigente en la actualidad. En todo caso, podemos adelantar que la discusión que tiende a hacer incompatibles los conceptos de ser y valor, será contraria a la posición de Maimónides. Se ha visto en la controversia de estos problemas que en la mayoria de las veces se trata de asignar al ser un valor, idea que supone rebajar el sentido del ser a una realidad que le es inferior, en otros términos, se trataria de sustituir una teorla del ser por una teorla del valor que se identifica con determinados objetos. Maimónides, en otra época, con otro lenguaje, intuye el problema 'qua' valor, revisa en el fondo de su conciencia los caminos de salida, busca en la fe la fuerza que necesita el pensamiento para realizarse, todo lo cual lo lleva, en ultimo término, a descubrir los elementos de justificación tan propios de las concepciones del valor, en las que éste no se opone al ser, contrariándolo, sino que, por el contrario, lo justifica en función de una teoria del bien. Utiliza el logos griego, que su tiempo recibe como herencia, pero lo limita, 
sometiéndolo a otro rigor y se apoya en la religión en la que encuentra la orientación que lo eleva a una concillación fundada en la profecia, verdad última que le permite avanzar un pensamiento universal. Nuestra tesis indica que el mecanismo que emplea Maimónides para lograr ese objetivo se encuentra en la compatibilización de los factores en juego, vale decir, toma en cuenta lo dado de la realidad, el proceso histórico, la profecía, la fe en Dios, sobre los que implanta un sistema normativo (deontologia) en la proyección de una forma de vida acorde con la enseñanza divina. En efecto, el percibe que los elementos que opera el hombre son limitados, generan una alvisión, un desgarramiento interior. El ser de la existencia es dividido, su interioridad es parcial y limitada, a diferencía del ser de Dios que es la interloridad absoluta. A consecuencia de esto, Maimonides descubre un conflicto permanente de tendenclas antagónicas, inconciliables entre razón y fe, teoria y praxis, filosofia y religión, vida humana y vida divina. El realiza un esfuerzo para subsanar las dificultades con las que tropieza intelecto $y$ voluntad que son limitaciones que reconocen ese mismo origen. Su objetivo, es lograr un tipo de comportamiento humano, en último término una forma de comprension de lo etico, que ajuste la vida del hombre a una incondicionalidad que sirva de fundamento a la acción. Esa es la razón por la que debe volver a plantearse la teoria de la inteligencia y de la voluntad, las concepciones del ser y del valor. Hay que atribuirle a Maimonides una clarividencia excepcional en estos asuntos que es, justamente, la versión que asumirá la filosofia en su evolución posterior.

Maimonides adelanta soluciones a la controversia de la metafisica intelectualista con la voluntarista. En la discusión su universalismo se apoya sólo en parte en la tradición occiden- 
tal porque más que en la razón el busca su fundamento en las verdades religlosas. En este sentido se acerca más al movimiento mistico medieval, con el que también tendrá sus diferencias. Sabemos que uno de los rasgos más salientes de la metafísica occidental es el caracter intelectualista en la medida que asume una visión racional del logos. Ella llega hasta sugerix una concepción teológica de caracter intelectual de la cual pende toda la reflexión metafísica. Según se ha dicho en más de una ocasión, somos herederos de la construcción ontológica de la prueba de la existencia de Dios de san Anselmo, que sirve de fundamento a toda la reflexión metafisica aristotelico-tomista. Maimonides no rechaza esta posición, sigue las aguas aristotelicas $y$ la interpretación que el hace de este pensamiento ejerce una influencla significativa en su época, cuyo es el caso de Santo Tomás que lo toma seriamente en cuenta. La contrapartida a este pensamiento radica en una metafisica voluntarista que se desenvuelve paralela a la anterior. Ella tiene su fundamento en la voluntad, aunque sin alcanzar la preeminencia de aquella. La pugna de inteligencia y voluntad en la metafisica tradicional es un debate no resuelto que tiene su origen en la teoria del acto, anterior para algunos a la teorla de la vision (theorein). Ambas posiciones tienen en la actualidad representantes de importancla. El intelectualismo reproduce una metafisica indicativa del ser oxiginada en el sex que es, frente a un voluntarismo que reconoce una metafisica del no ser, propia de la teoria de la acción tan caracteristica de las concepciones del valor. Maimónides, con una anticlpación sorprendente, al aceptar el valor de la profecia, abre caminos de acceso a la solución de estos problemas fllosbficos. No obstante, su pensamiento en este punto requiere de una precisión. En la controversia filosofica del ser que es $y$ del no ser que es, tan abundante en nuestros dias, que 
en el fondo de la disputa de un ontologismo indicativo (del ser que es) y de un ontologismo de los valores (del no ser que es), pensamos que Maimónides no percibe esta cuestión en toda su extension. Mejor aún, es dificil suponer en este pensador una concepción de Dios que no fuese la indicativa, para el Dios simplemente es. Ahora, pudiera pensarse que él se adhiere a una teoria del ser que no es por cuanto apoya el voluntarismo metafísico de modo destacable, y sabemos que esta doctrina otorga más fuerza a una concepción del ser que no es la de una tesis indicativa. Queda, entonces, por preguntarse en que consiste este voluntarismo de Maimonides. Creemos que la solución viene de la provisión normativa propia de una estructura del deber ser, que se fundamenta en el cumplimiento de la profecia, que consagra la aceptación del mandato de Dios.

En verdad, la discusión se plantea esterlimente al tratar de dilucidar la preeminencia de la inteligencia sobre la voluntad $y$ viceversa. Este camino se encuentra agotado $y$ se descubre aquí, probablemente, el ifmite de la metafisica. Aceptar la primacia de un elemento sobre el otro no resuelve la cuestion de fondo. La teoria gue asuma semejante dicotomia o deje de lado" uno de estos elementos en favor del otro, no satisface adecuadamente la solución del problema, vale decir; acota de modo impropio, reductivamente, la realidad en examen. Maimonides prevee esta situación, anticipandose al asunto, trata de compatibilizar voluntad e inteligencia, contribuyendo de esta manera a la formulación de una interpretación más armónica. Reconoce la competencia del saber humano en algunos aspectós de la realidad (las cuestiones sublunares), pero en otros busca su fundamento directamente en la verdad de. Dios. Compatibiliza el pensamiento de Aristoteles con la profecia. Indica que todo 10 
que ha dicho el Estagirita sobre las cosas sublunares "es, sin duda, verdad", pero vuelve sobre la peculiaridad de lo divino al afirmar que nadie sabe nada de 10 que hay en el cielo, a causa de lo cual, 1o que le queda a la existencia es la inspiración divina, cuyos contenidos el pensador ratifica con su obra y con su propia vida. La profecia es la única capaz de explicar la existencia individual y concreta del hombre. En ella radica una posibilidad de díalogo con Dios. El pensamiento del mundo se satisface con la experiencia humana racional que, llevada al exceso, nos aleja de Dios y de la verdad absoluta. El pensar exaltado por la razón más de lo conveniente, aleja al hombre de su objetivo. Aunque, necesario es decirlo,el cambio de la razón por cualquier otro logos o instrumento que no sea el divino, no es mucho lo que va a acercar la filosofia a la religión. Con esto resuelve el problema del conocimiento de lo humano y lo divino, aplicando a la vida ética y juridica una teoría voluntarista llena de prescripciones y sentido normativa (su intento de la Micchna Torá asi lo demuestra). Por el lado de la teoría de la voluntad también. se vincula al pensamiento aristotélico, sin dejar por ello de rectificarlo en algunos aspectos.

El considera que el pensamiento racional es un instrumento imprescindible para el conocimiento de la realidad, pero indica que en determinadas situaciones esa propiedad se vuelve opaca, no penetra al fondo de ella. De aqui surge el sofisma mayor: negar la existencia de aquello que la razón no puede conocer, es un abuso del racionalismo. Mutatis mutandi, desconocer la función de la razón porque no satisface todas las areas de la experiencia un exceso del irracionalismo.

Ciertas investigaciones filosoficas, al poner al 
descubierto las limitaciones de la razón, han derivado al irracionalismo. En el transcurso del tiempo, la teoria de los valores ha ido asumiendo un papel cada vez más importante en este problema reconociendo en algunas de estas materias, un antecedente remoto de Maimónides, pero sin entregarse al irracionalismo. Tiene en común con dicha teoria el sentido de lo normativo, como exigencia del deber ser, y el significado de la profecia; esta ultima, por cierto, con similitudes en la forma como se afianza en la teoría filosofica pero con variaciones de contenido que pueden ser enormes según sea el pensador que se tenga en consideración (pensemos, por ejemplo, en las diferencias sobre un mismo tópico del pensamiento de un scheler o de un sartre).

Piensa que la razón está habilitada, en áltimo término, para el conocimiento de la realidad y sus limitaciones vienen tan solo de su relación con el mundo suprasensible. Del mismo modo el pensamiento religioso que él defiende, consistente y alquitarado, no puede compatibilizarse con la idea del ninilismo, contra el cual se dispone, apoyando su doctrina en la seguridad que le proporciona la fe en Dios. Por ello las dificultades que enfrenta la teoria en el pensamiento filosófico, se van ajustando en Maimónides en la medida en que otorga a cada uno de estos elementos una ubicación dentro de una experiencia universal.

En efecto, el argumento del irracionalismo radica en que la inteligencia categoriza la realidad a través de la razón, limitandola y desvirtuándola, procedimiento que resuita, a la postre, insuficiente para el conocimiento puesto que desfigura la realidad. Se produce una incompatibilidad de concepto $y$ objeto $y$ se hacen evidentes las limitaciones de la verdad como 
adaequatio. Esta situación proviene del hecho que desde un comienzo la metafísica tradicional le ha dado a la vision (theorein) una importancla decisiva: el conocimiento que proviene de ella es anterior a todo hacer de la vida practica, pero el ejercicio de la razón aplicada a este propósito es insuficiente. La voluntad no ha podido vencer la preferencia del conocimiento sobre la acción; aunque, a trechos la ha considerado como uno de los elementos constitutivos de la realidad. Esa circunstancia no ha sido, sin embargo, bastante fuerte para romper la identidad de realidad y razón." Es probable que dicha identidad revele efectivamente la justa correspondencia de estos factores. Pues bien, de allí surge una nueva vía que da lugar a una forma de ser propla fundada en el afianzamiento de la tendencia relígiosa. En el enclave crucial que conduce a la consolidación de este movimiento de universalizacion en la actitud religiosa, el papel de Maimónides es decisivo e imprescindible, porque destruye el irracionalismo que se levanta naturalmente de esta "controversia y concilia de este modo una metafisica del logos con una teoria de la acción compatible con los factores en juego, mejor aún, su rol reviste más importancia en la medida que orienta el sistema etico y politico de la comunidad judia en una forma definida del conducirse historico.

El pensamiento de Maimonides ha dado margen a un proceso formador. La formación, concepto de un pensamiento elevado e interior, es el modo de percibir del creyente que procede de acuerdo a la verdad revelada. El pensamiento judio se ha formado en torno a la interpretación de los textos sagraaos que el mismo ha ayudado a comentar, su inserción en esa cultura ha sido posible gracias a la compenetración reciproca de la fe $y$ el.logos, ayudada en sus comienzos gracias a la interpretación 
de las fuentes griegas. Por ello algunas de estas caracteristicas encuentran su origen en el estudio de los contenidos de $1 a^{\prime}$ cultura europea.

La aproximación a Maimonides desde esta perspectiva hace visible su vigencia $y$ actualidad. Esto recuerda la sentencia crociana que, juiciosamente, afirma el caracter de toda historia verdadera, en el sentido de ser historia contemporánea. A siglos de la época del pensador judio-español todavia están vigentes las razones que autorizan para preguntarse por su actualidad, vale decir, por su contemporaneidad. Anticipando toda posible conclusion se puede afirmar gue la historia de Maimónides es la de un hombre que muestra la ejemplaridad de una 'magistra vitaer'. Cobra importancia en este contexto la pregunta por el contenido de la historia sobre todo cuando esta se vincula al desarrollo auténtico de la vida de un pueblo. Actualidad $y$ contenido historico quieren significar en este planteamiento la conexión de una manera de pensar vinculada a toda una comunidad, $y$ a un intérprete de ese fenomeno, certero de la doctrina vetusta, que generó en el medioevo consecuencias culturales que llegan hasta nuestros días. Esa época, unidas a otras que también conforman la vida de ese pueblo, traducen en su conjunto una filosofía que afirma el mandamiento biblico: Escucha Israel, yo soy tu Dios.

De las prescxipciones del texto de la ley judia, la Mishná, el Talmud o los famosos comentarios de Maimónides, se hace presente algo permanente que lleva la simiente de la evolución posterior. La historia ilumina una tradición, la vincula a una forma de vida $y$ la hace experiencia significativa. La fuerza del pasado se proyecta al presente, el mensaje del tiempo dis- 
tante se hace nuestro. La historla se transforma en historia propla, efectual, de contenidos. De mayor realce todavía cuando la vida de un hombre, su pensamiento y su acción, penetra en todas las oquedades de la experiencia vivida y se identifica con la historia de un pueblo. Esta se presenta como una forma de tomar en serio 10 gue el hombre y la comunidad han hecho en el pasado. En términos de nuestro ortega y Gasset, el sentido de la enseñanza del pasado construye la historia. El hombre realiza su proyectode vida porque cuenta con la historia que se le hace presente cotidianamente, en el ejercicio del culto, en la transacción comercial, en la práctica polftica. Este juiclo no tiene reproche en el caso de Maimónides, en la medida que se acepte que el pensamiento recibe una orientación decisiva de la profecia, única que tiene la posibilidad de establecer el sentido total de la existencia.

Semejante conclusión demuestra que la historia de la conclencia religlosa es la conciliación de la vida vivida con Dios. Vivencia que no se encuentra encapsulada en una profundidad arqueológica, $\mathrm{ni}$ tampoco consiste en un estático amontonamiento de experiencias inutiles $y$ sin trascendencia, hacinamiento de ruinas escasamente recordatorias. Por el contrario, la vuelta a Maimónides, a su actualidad, hace necesario trasladarse al presente y proyectarse al futuro. El porvenir se posesiona del pasado, la historia tiene un sentido ordenado, deja de ser un mero decurso de peripecias sin significación para ganar un sentido más pleno.

La historia del pasado $y$ del presente hacer ver su actualidad, apreciandose la consecuencia que ella tiene en una tradición que se ha afianzado por siglos; esto es algo propio $y$ 
excepcional que se vincula de modo especifico a la obra de Maimónides. Esta es la epopeya de la conciencla religiosa de caracter vinculante a un todo superior que se plantea en forma central con ocasión del pensamiento de este filósofo; se trata en este contexto de : una reflexión que contribuye a reforzar una categorfa hermeneutica general que ayuda a comprender la coherencia de un pensamiento religioso a partir de algunos criterios filosoficos. Los grandes desarrollos de la filosofia actual, como pensamiento de futurición, profecia divina cumplida $y$ autoprofecia, se encuentran en este ahondamiento. Desde este pensamiento, la historia del pueblo de Israel se hace inteligible, y más comprensible a partir de sus rafces metafisicas, en los multiples aspectos, sobre los cuales la conciencia histórica y la vida presente deben volver una y otra vez.

Se expresa en Maimónides un plan de claridad que atribuimos a un propósito de universalización de la creencia y la" práctica religiosa. Del mismo modo, siempre vínculado a ese afán, la obra descubre también la idea de sistema, aspiración del filósofo a una posibilidad de coherencia en la comprensión total del pensamiento judio en una proyección historica. Maimonides sigue en esto la recomendación de esa regla de interpretación" que indica que a la "distancia esencial entre lo general $y$ lo concreto se añada todavia la distancia histórica, capaz,de desencadenar una productividad hermenéutica propia":

En efecto, la cultura hebrea aparece regida por una evolución intelectual que muestra aspectos variados, cualidad gue es posible identificar en la historia del pueblo judio. En 616 . 
primer lugar, se observa que a través del tiempo la cultura presenta un orden sucesivo de tendencias parciales que admiten explicaciones de carácter analitico, seguidas de otras, consolidación de las anteriores, que ofrecen un caracter sintético. Son, como dice Heschel, verdaderos ritmos que la historia constata y reconoce en su desarrollo cultural. En realidad, corresponden a los elementos parclales y de detalle de la vida individual y comunitaria, partes internas, divididas de una totalidad, verdadera analftica de lo singular que posteriormente se recogen en una totalidad, sintesis de la situación que conduce a un nuevo planteamiento de cristalización historica. En segundo lugar, $y$ dentro de estos ritmos, se descubre un conflicto permanente de elementos antagónicos, en cierta medida inconciliables, entre razón y fe, teoria y praxis, filosofia y religion, vida humana $y$ vida divina, etc.

Ambos ordenes de problemas son examinados por Maimónides; el presiente la necesidad de abarcarlos y resolverlos en su contradicción, única manera de consolidar desde alli los rasgos estables de la vida espiritual del pueblo. Esta ultima fase la realiza principalmente en la aplicación del orden normativo que debe regir la comunidad. El filósofo lleva a la práctica la vivencia de lo religioso empleando los mecanismos de la interpretación de la ley. En general, las reglas de interpretación que él utiliza son las que se denominan de una hermenéutica de tipo normativo y reproductivo, aungue a trechos sus argumentos se acercan al lado filosofico y cognitivo de la interpretación de los asuntos que trata.

Gran parte de su trabajo de legislador, los comentarios a la ley judia, a la Mishná y al Talmud, tratan de conci- 
liar los factores contradictorios de la realidad. Por ello. afirmamos que la labor de Maimónides lleva implicita una actitud fliosoflca fundamental, una 'ratio' de sistema que dispone de una coherencia al tratar de hacer compatibles los aspectos dispares de su comunidad. Malmónides pone todo su esfuerzo en subsanar los efectos que generan los factores de división en el hombre y su desgarramiento interior; esta actitud cobra especlal interés con posterioridad dado que su objetivo es crear en la comprension de lo religioso un tipo de conducta que ajuste inteligencia $y$ voluntad, filosofia y religión en una explicación unica $y$ consecuente.

Hasta aqui el argumento describe en una perspectiva histórica la personalidad del filósofo, y el legislador. Pero la descripción es insuficiente; queda todavia sin formular su principal propósito y su mejor logro, objetivo fundamental de su preocupacion: la necesidad de formar al pueblo judio en la ensenanza de la profecia. Piensa en la convivencia de internarlo en los problemas que va a sufrir en el futuro y quiere prepararlo para su salvación, redimirlo de los peligros que lo amenazan y que vendrán de acuerdo a los anuncios de la profecía.

Agui se observa que Maimónides es hombre de Dios, supera el conflicto de intelectualismo $y$ voluntarismo en las perspectivas de asentar un esquematismo normativo que acoja la sabiduria de la profecia en la praxis del pueblo judio. Sorprende favorablemente la gravedad que le atribuye a la enseñanza de los libros sagrados. En efecto, piensa con seriedac en los tiempos por venir $y$ cree firmemente en ellos. su preocupación nace de que el pueblo de Dios, como lo dice la profecia, será mortalmente herldo. Llama la atención ante el hecho que grupos 
diversos usan las mismas doctrinas proféticas para afianzar por igual antiguas $y$ nuevas creencias. La misma palabra produce efectos distintos, en circunstancia que, viniendo de Dios, deberian tener el mismo significado. Su observación indica que cristianos $y$ musulmanes emplean la verdad revelada para fines propios. No sera posible alcanzar, entonces, alguna objetividad en vista a lograr la conciliación entre estos pueblos.

Trata de alcanzar parte de estos objetivos por medio de la enseñanza de la ley judia que el vincula a las más variadas cuestiones filosoficas. Ha ganado fama de libre pensador por la libertad que tiene para moverse en la filosofia de los gentiles, dejando vagar sus aficiones en los problemas de la interpretación de la enseñanza judia. Esta libertad le permite al filosofo ver con claridad la enseñanza de la tradición, en una hermenéutica que le indica, en último término, que la "configuración continuada de la vida moral y social en general, reposa siempre sobre un hacer consciente que se asume en libertad" '.

La Mishná es una compilación de las leyes más tradiclonales de los judios, consignadas en las escuelas farisaicas. La palabra Mishna proviene del neohebreo 'mishnah' que significa instrucción, ley oral, que viene a su vez del hebreo 'shanah', gue significa repetir. Aunque en el hebreo post-biblico se destacan más las expresiones enseñar, instruir, ilustrar la ley, que repite la enseñanza tradicional de las escrituras. Aqui radica el énfasis de la interpretación de Maimónides y en eso su obra insistirá incansablemente. Será el punto de arranque del proceso formador que habilite a su pueblo en las practicas 
comunitarlas.

El Talmud, el Libro de los judios, es la continuación natural de los comentarios de la Mishna. Contiene una extensa compliación de los preceptos enseñados por sus doctores más autorizados. La expresión tiene su origen en...la palabra Talmud $y$ ésta de Lamad, que significa aprender. El Talmud consagra en sus disposiciones la tradición, doctrinas, vida social $y$, politica $y$ otras materias que el pueblo respeta rigurosamente. Se supone que el' Libro fue escrito despues de la destrucción de Jerusalén. La historia judia relata que con posterioridad a ese acontecimiento, los doctores buscaron la manera de alcanzar la unidad religiosa tan deteriorada por los hechos ocurridos. Con este proposito se concentraron al estudio de sus leyes $y$ tradlciones. La Torá, libro de la ley hebrea, palabra que viene del latin 'thora' $y$ ésta del hebreo 'tora', significa el fundamento, que corresponde al "to $t i$ en Einal" de los griegos.

La Mishna es el resultado de esta actividad persistente de la repetición de la ley o segunda ley. Los comentarios de la Mishna forman la Guemara. Esta y la Mishna constituyen tradicionalmente lo que se llama el Talmud o Libro de los judíos. El trabajo de confección de la Mishnáse debe a los rabinos cuyas enseñanzas se extienden del año 70 al año 250 de. nuestra era, en las escuelas de Tzippor y Tiberiades.

En el trabajo de interpretación de la ley hebrea, Maimonides tuvo que decidirse entre asumir el papel de comentador de la ley o codificador de la misma; él cpto por aquello que pone el mayor énfasis en la decisión y en los aspectos de aplicación pragmática de la ley. Debla decidirse entre el Talmud o 
la Mishná o su comentario. Slendo distinto el tratamiento de uno $y$ otros. El Talmud trata de convencer, plantea las objeciones recaldas en cada decisión, 10 que hace este texto extremadamente complejo y a veces confuso. Maimónides prefiare el método de la Mishná, obra autónoma de carácter prescriptivo, sin objeciones ni justificaciones, que se presenta independilente de las teorias que tratan de explicar la decisión.

El método de Maimónides se impuso desde el comienzo en el mundo judio. Tardiamente aparecieron critilcas que destacaban los defectos del procedimiento seguido por el filosofo, a consecuencia de lo cual él tuvo que hacer aclaraciones a sus comentarios, y sufrió molestias hacia el término de sus dias ocasionadas por esta causa. En una de las inscripciones de su tumba se consigna "Aqui yace Moisés Maimónides, el herético desterradon, alusión que viene con seguridad de la intexpretación de los textos examinados.

La necesidad de completar la ensefianza de la comunidad, es la meta inmediata que se plantea Maimonides. Le preocupa que su pueblo descuide la reflexión de la fllosofia, que 10 conduce a una vida no examinada que le acarrea, a su juicio, graves consecuencias, siendo éste uno de los motivos que "10 inducen a preparar a su gente en estas materias. En efecto, el piensa que otras naciones tienen especial interés en anular las cualidades y virtudes de Israel, destruir su ciencia, sus libros, sus sabios. Recuerda a Isalas: "y la sabiduria de sus sabios perecerá, $y$ la inteligencia dé sus hombres desaparecera" (Isaias XXIX, 14). El interés de Maimónides es fortalecer a su pueblo para evitar los males que proviener de otros paises: "Seremos mezclados a esas naciones, sus ofiniones pasarán a 
nosotros, as 1 como sus costumbres $y$ sus acciones"? perdiéndose de ese modo la calidad de pueblo elegido.

Siempre se apoya en el Libro sagrado, sin embargo los pensamientos de la Biblia, nos dice, se encuentran escondidos, como una perla que alguien ha perdido en una casa, oscura $y$ llena de muebles. La perla existe pero el honbre no la ve $y$ no sabe donde está: El pueblo toma la palabra a la letra y no busca el sentido escondido que hay en ella. Indica que si bien las enseñanzas de la filosofia son claras, la: de las escrituras lo son solo parciales en razón del empleo de la parábola; por eso le es preciso explicar el alcance ultimo de sus textos.

La preocupación mayor del maestro es la de preparar al pueblo. El filosofo estima que la adquisición de los mecanismos de representación del mundo son la resultante de fuentes filosoficas unidas a las de la tradición. El esfuerzo de conciliación de estos dos momentos conduce a Maimónides al pensamiento universal. No debe estimarse esta afirmación cono una estación de término o epilogo en la evolución intelectual del pensador, por el contrario, se trata más bien de un inicio, de un prologo, comlenzo en . el que debe perseverarse hasta alcanzar los frutos de esa enseñanza.

El concepto de creación del mundo tiene mucha importancia en la enseñanza de Maimónides. El julaismo previene que Dios ha creado el mundo de la nada y que un tiempo estuvo donde El existia y no fuera de El. El acto de creación ex nihilo es

Maimónides. Guia de los extraviados T. II, 11, p. 96.

Maimónides. Op. cit. p. 18. 
propio de Dios.

Dicha enseñanza está en contradicción con Aristoteles, quien sostiene que el universo entero, tal como es, ha sido y será slempre asi, el tiempo $y$ el movimiento son eternos y permanentes. Dios ha dado la existencia al mundo, pero no lo ha creado de donde nada existia. Lo que indica çue Dios es responsable de la existencia del mundo pero no ha realizado un acto especial para su creación, porque Axistóteles, al igual que el pensamiento griego, piensa que no es posible la creación de la nada (ex nihilo nihil fit). La fllosofla oficlal de la epoca de Malmónides estimaba en forma inconclusa que Aristoteles habla probado la eternidad del mundo. No obstante, Maimónides piensa sobre el particular que la cuestión de saber si el mundo ha sido creado $o$ es eterno no puede ser resuelto por: prueba alguna $y$ que, ciertamente, el Estagirita tampoco habia logrado ese objetivo. Los sablos, sefiala, han proclamado la eternidad del mundo Y han rechazado la palabra de los profetas; ha causa de lo cual los han inhabilitado porque éstos, además, no se expresan ni argumentan al estilo racional, situación que ha hecho que los sabios hayan caldo en una inobservancia apreciable al no percatarse que los profetas proclaman la palabra de Dios, siendo esto justamente lo que debe pensarse sobre el partil:ular:

La discusion filosofica lleva a una alternativa que se plantea en terminos de aceptar la libre voluntad de Dios o la necesidad divina, dicho en otros términos de considerar a Dios amo $y$ soberano del mundo, que reina a voluntad $y$ dispone del milagro o la de pensar a Dios ligado eternamente a un orden 
natural inmutable.

Parece evidente que Maimónides acepta la primera de estas postulaciones. El hombre es incapaz de comprender la creación $y$ el origen de las especies. La inteligencia es 1imitada para conocer estas realidades.: La teorla de la emanación, que gulere explicar el orden del mundo por leyes necesarias, es insuficiente para comprender la existencia de las variedades.

Si se admite que el mundo fue creado el milagro es posible, pero "sl se sostiene que el mundo es asi por necesidad... se negarán todos los textos. de la ley". Por eso se separa del conocimiento $y$ se entrega a la fe, aceptando el milagro $y$ el poder divino. Curiosamente siglos después, el padre del existencialismo hará el mismo esfuerzo, apoyándose en la fuerza del milagro que encierra el poder de Dios. En efecto, Kirkegaard (1813-1855), se anticipa a todo determinismo teologico que pudiera limitar el poder de Dios. Por eso no se acepta el argumento de las 'veritates emancipateo "Deo", verdades Independientes que están en la naturaleza de Dios, porque ellas reducen la 1 ibertad del ser supremo.

Sin embargo, Maimónides no suprime la metafisica ni la teorla de la realidad. En su polémica con la secta de los motazales, quienes no aceptan la noción de causalidad porque estiman que el ser no es una ley sino "un habito de la naturaleza" o una costumbre instituida por Dios en la naturaleza, se pone de lado del sistema aristotélico $y$ lo deflende al sostener que "el ser no se acomoda a las opiniones, pero las opiniones verdaderas se 
acomodan al Ser"? Lo que indica que su discrepancia con Aristoteles está más bien circunscrita a la cuestión de la creación del mundo, acogiendo en este punto la ensefianza de la profecia. Ella es la única, en efecto, que "explica las cosas a las cuales la facultad especulativa no sabrla llegar. Compatibiliza el pensamiento Aristotélico con la profecia al afirmar que la fllosofla del Estagirita sobre las cosas del mundo es correcta $y$ debe ser aceptada. Reserva sin embargo, el conocimiento del mundo suprasensible y los asuntos de la divinidad, para la profecia. Se apoya insistentemente en la inspiración divina que es el recurso que le queda al hombre. La profecla es la anica capaz de explicar la existencia individual concreta la que abre una posibilidad de díalogo con Dios. Cita la escritura: "Yo le hablo boca a boca": $y$ en otra parte: "Molsés, Aron y Myriam deseaban un beso del señor" 2 .

Maimonides le atribuye enorme importancia a la meditación sobre Dios, fundamento de la sabidurla. El filosofo se pregunta sobre el conocimiento de Dios, 10 que piensa el ser divino, las cualidades que se le pueden atribuir. He aqui el problema de Maimonides que trata de solucionar; quiere llegar al conocimiento de Dios a través de eliminaciones negativas, una suerte de negación de las imperfecciones, único medio que el considera idoneo para aproximarse a ese conocimiento superior.

1 Maimbnides. T. I, 71, p. 343.

- Maimonides. T. II, 16, p. 119.

- Maimónides. Op. cit. T. I, p. 195.

20 Maimónides. Op. cit. T. I, p. 195. 
Antecedentes de esta forma de proponer el asunto se encuentran en Platón. Este filosofo utiliza la teología negativa como un procedimiento que le permite descartar de la naturaleza de Dios la imperfección de los demás seres. Siguiendo esa línea se encuentra también la escuela judia de Alejandría, con filon, el platón judio, y la escuela griega de Alejandría con plotino. En buenas cuentas se prefiere la negación sobre la afirmación porque evidencia mejor la distancia infinita entre Dios $y$ el mundo. En la obra de Dionisio el Areopagita, también aparecen las locuciones negativas para referirse a Dios, que no significa privación sino exceso: la ausencia de sustancia es la sustancia infinita, la ausencia de vida, la vida suprema, etc. (De divinus nominibus).

Maimónides justifica su argumento de.. la siguiente manera: la palabra eterno, por ejemplo, designa algo en relación con el tiempo, accidente del movimiento que completa la naturaleza de los cuerpos, pero limita la realidad divina. En la discusión con los motazales, rechaza su forma de pensar porque limitan la prueba de la existencia de Dios, restringiendo el poder divino. Ellos admiten que el mundo ha sido creado en un acto que supone la existencia de un creador, pero Maimónides reprocha la insuficiencia del argumento; piensa que de esa forma se condiciona la existencia de Dios al origen del mundo, situación que, a su juicio, limita la potencia del hacedor. La proposicion que atribuye facultades positivas a Dios tiene el inconveniente de limitar las otras cualidades que también le pertenecen en un abanico infinito de posibilidades. Este argumento ha sido frecuente en la filosofia contemporanea. El concepto de verdad como aletheia, verbigracia, que ilumina $y$ oculta al ser por igual, lleva esta provisión. No es posible una teoría sobre 
el ser del hombre, por ejemplo, puesto que cada vez que se afirma algo sobre su ser se excluye otra posibilidad significativa que eventualmente pudiera acreditarse.

Se ha tratado de descubrir una contradicción en Malmonides por el hecho que este afirma que Dios fiensa. Se argumenta en su contra de la siguiente manera: ¿Se fuede justificar la afirmación que Dios plensa si no tenemos de Fil ninguna experiencia?. Lo mismo ocurre con la idea que asevera gue el pensamiento emana de Dios, fuente de todo pensamiento. El se define afirmando que no hay una contradicción en estos juicios porque ellos deben ser interpretados de acuerdo con la enseñanza de la profecia que ilumina ampliamente las materias profias de Dios. Afirma que 10 que no aprueba el pensamiento racional, lo justifica la profecia, que él apoya en un acto de fe. Vemcs en este caso que el argumento es distinto al anterior. Alla se rechazan las locuciones positivas porque toda afirmación limita el poder de Dios que es infinito. Aqui se acepta la prueba del pensamiento divino por causa de las limitaciones e incapacidades de la razón humana. Por ello, la meditación por la negación, la dialectica negativa, es un método lógico que Maimónides construye con los elementos de la profecia, suma asi, entonces, a la comprensión filosofica, las cualidades positivas de la profecia a la que no renunciará jamás.

La profecia la posee el hombre excefcional y aunque el filosofo está capacitado para transmitirla, ella no es un dominio de fácil acceso. Reprende a su discifulo Joseph cuando, explayándose en esta materia, pretende atribuirse cualidades que no tiene. Piensa que el no comprende los tropiezos del pensamiento frente a los contenidos de la profecía $y$, sobre todo, la 
sabiduria que se requiere para formular estas verdades.

Estos planteamientos transcurren por la filosofia hasta nuestros dias, como una tarea ardua para el pensar raclonal. El saber del no saber de Nicolás de cusa encuentra un antecedente en la fe que no es descartado filosoficamente. Kirkegaard, siguiendo el pensamiento teológico moderno, ha aceptado de modo pleno la misma argumentación, basandose, al igual que Maimónides, en las fuentes sagradas. Y en nuestro propio siglo, el concepto de lo pre-ontologico (Heldeger por ejempio) en cierta medida admite en la descripción fenomenológica una descripción anticipada del conocimiento de la totalldad.

La profecia integra la realidad, no la descarta ni la separa de la experiencia del hombre. Dice Maimónides sobre la realidad que: "En el ser no hay otra cosa que Dios y sus obras, estas ultimas son todo lo que el ser enclerra, no hay otra manera de percibir a Dios que por sus obras, éstas son las que indican su existencia $y$ esto es 10 que hay que creer a este respecto"'s.

Maimónides siente que el fin de los tiempos se aproxima como lo indican las escrituras. El signo sera la persecución del pueblo judio, después de la cual vendra la liberación. Recuexda a este propósito las enseñanzas del profeta Daniel sobre los tiempos mesiánicos que serán precedidos por las persecuciones que sufrira el pueblo elegido.

Padre de su pueblo, preocupado de su vida espiritual,

Maimónides op. cit. T. I, 24, p. 120. 
llama la atención, recomienda y previene, tiene claridad de 10 que serán esos tiempos. No desea para Israel un poder universal de subyugación a otros pueblos, 10 que seria incurrir en los mismos vicios que el observa en su época. Cree que los nuevos tiempos serán de goce de la verdad divina, de cumplimiento de la voluntad suprema: "la tierra estará plena del conocimiento de Dios".

Aunque movido por la esperanza mesiánica, no tiene presentimientos de la nueva época, porque sabe que nadie podrá determinar esos tíempos, las palabras quedarán selladas y ocultas: será el cumplimiento de la profecia de Isaías.

Se plantea con todo rigor la cuestión del mal, que se presenta en las contrariedades que sufre la existencia. No obstante, su misión afianza una concepción del bien. No es el mal 10 que se acredita; lo que se observa con cortos intervalos en los que el bien simplemente no actúa, interrupciones de su continuidad; sólo el bien es real y proviene de Dlos. No hay en Maimónides una teoría del mal como la que se plantea más adelante el ldealismo alemán, principalmente con schelling, porque para el pensador judio no existe la posibilidad de la libertad humana abierta al bien y al mal.

Desde que el hombre tiene un conocimiento cierto de la divinidad, reconoce que la verdadera felicidad, consiste en el conocimiento de Dios, que está reservado a todos aguellos que le conocen; en la proximidad de Dlos ninguna de estas calamidades podrá turbar al nombre $\mathrm{e}^{22}$. 
Iniciado en la imagen antropocentrista del universo, sus reflexiones posteriores la descartan definitivamente. No debe juzgarse el mundo sollo por el individuo humano; el "ignorante se imagina que el universo entero no existe más que por su persona como si no hubiera otro ser que el solo" y en otra parte dice "el hombre debe saber lo que vale en el conjunto universal y no creer que el universo no existe más que por su persona y la especie humana es bien poca cosa en relación al mundo superior... a las esferas y los astrosint.

La pregunta por la utilidad del análisis lingũistico en las interpretaciones de la profecia, lo conduce a examinar la cuestión de la validez y grado de competencia de la ciencia en los asuntos de esta naturaleza, sobre todo porque reconoce que existe aqui un componente que dificilmente se somete a la metodologia cientifica. No discute el valor del analisis cientifico en los problemas religiosos, pero sostiene con igual evidencia que en algunas materias el problema de fondo está más alla de los criterios propiamente cientificos.

En la comprensión de la experiencia historica se pregunta hasta donde puede llegar la ciencia. Este es el mismo mensaje final de la Fenomenologia del Espiritu. Maimónides se mueve en esta distinción del pensamiento de Hegel. La cuestión que encierra la pregunta de hasta donde llega la ciencia (Bis Hierher ist das Wissenschaft gekommen) se amplia más alla de esta prevision porque ahora se presenta al debate el problema útimo de saber hasta donde llega la conciencia (Bis hierher ist

13 Maimónides. T. III Op. cit., 23, p. 68.

14 Maimonides T. 111 op. cit., 23, p. 68. 
das Bewusstseyn: gekommen). La justificación de este asunto es obvia en este contexto: el sentido último de la profecia no es alcanzado por la clencia $y$ parece evidente que admitir este hecho conduce a la conciencia religiosa que amplia el conocimiento puramente cientifico.

La hermenéutica trata de aclarar en que consiste la experiencia histórica. La profecia forma parte de esta experiencía y la duda que puede levantar su significado, no es objeto de problema en cuanto hecho histórico porque esta a la vista. Ella consiste, como dice Gadamer, en "la tarea de la proclamación de la fe en su traducción a la palabraks, de alli nace su posibilidad de ser sometida al tratamiento cientifico. En este sentido, es indudable que la profecla genera un contenido de verdad. Lo que se afirma cientificamente es que, independencia de la vinculación ultima, que puede ser dudosa, existe una manifestación historica que tiene un peso indudable, que trasunta una experiencia de verdad. En esta dirección su situación es similar a la de la metafisica, la poesia $y$, en algunos casos, a las ciencias sociales; podria dudarse de la verdad de sus contenidos, pero nadie puede dudar que ellas reflejan como preocupación fundamental una actitud humana objetivamente demostrada, lo que corresponde a una verdad manifiesta. La verdad de la metafísica, por ejemplo, no es tanto que haya resuelto los problemas que aborda como el hecho que ella misma se define como ciencia en función de los problemas que caen en la esfera de su preocupación.

La afirmación de una hermeneutica, idónea para formu- 
lar el análisis clentifico de la profecia, debe examinarse cuidadosamente. Se introduce, a nuestro juicio, un criterio de evaluación de los contenidos historicos, entre los cuales se cuenta a la profecia. En esa virtud, el analisis permite fljar los Ilmites dentro de los cuales ella se mueve como experiencia historica, aunque, obviamente, deja sin resilver la pregunta asociada a esa, en orden a que la hermenéutiza puede someter a analisis los contenidos de la fe en su significación última. En otros términos, el rendimiento de la investigación se relaciona con la posibilidad de conocimiento cientifico, en la que funge como hecho historico, incluyéndose la fe y la profecía en este mismo acontecer. En esta dirección sus aportes son positivos, decantan una verdad, pero es indudable que este mecanismo tiene una limitación, porque "no podemos dejarnos inducir al error de que el problema de la hermenéutica solo se plantea desde el punto de vista del moderno historicismorar, ya que siempre hay un sentido último, que contiene la verdad revelada, que se escapa a toda previsión científica.

La hermenéutica puede resolver satisfactoriamente los problemas historicos al modo cientifico $y$, dentro de esa misma posibilidad, esta en condiciones de formular, de acuerdo a la clencia, los alcances $y$ "limites de su pregunta, he Incluso de 10 que es inaccesible para una lógica positiva, por no ser conforme a esos presupuestos. E1 asunto as 1 planteado decanta una verdad que tiene todas las virtudes y limitaciones que nos indican los epistemologos. Por eso, formularse los limites de la pregunta es una cuestion de filosofia que afecta a la ciencia. El intento kantiano de la primera critica es, precisamente, el esquematismo 
que da cuenta de una forma de desarrollo de estas posibilidades.

En esta proyección, Maimónides resuelve bien el asunto de acuerdo a los criterios de la hermenéutica fllosofica moderna, dejando el contenido de la profecia, cono problema último, entregado a una cuestión propia de la fe. Se produce un ordenamiento de la experiencia en cuanto se refiere a la profecia, en la que se compatibiliza el sentido historico con el contenido ultimo que ella soporta.

Por este motivo se insiste que el intento de Maimónides es uno de los esfuerzos de mayor importancia que ha producido la historia del pensamiento en este propssito de conciliar los elementos dispares de la vida humana.

El uso de la razón en el tratamiento de los contenidos de la profecía desvirtúa su realidad y la cualidad de verdad que contiene. La verdad divina no puede ser comprendida por los criterios humanos. Sólo el profeta puede alzarse y mirar sobre los tiempos. Por eso Maimónides constituye un ejemplo excepcional en esta materia, puesto que el trata de introducir en el sistema normativo, en una estructura de deber ser, las conductas empapadas de la sabidurla que proviene de Dios.

La experiencia historica indica que no es posible ir más allá de la vida. La ensenanza del historicismo, y la del propio Dilthey en el mismo sentido, parece ser definitiva. Sin embargo, aplicar estas conclusiones a la profecla es inadecuado porgue ella está más allá de la vida humana; siendo correcta la apreciación de Maimónides sobre este asunto, insistiendo en apoyarse en la profecia y la fe. 
El pueblo de Israel siguió respetuosamente a su maestro pero con cierta distancia. Sus doctrinas no siempre tuvieron el favor popular $y$, a veces, otras interpretaciones fueron ganando una aceptación mayor. No obstante en los siglos posteriores su figuxa se torna inmensa, constituyendo uno de los pilares inconmovibles de la cultura judia y universal. Su muerte acaecida el año 1204 lo sorprende en Fostat, El Calro, de alli fue llevado a Tiberlades, en donde fue enterrado. Su tumba tiene inscrita la siguiente leyenda:

Aqui yace un hombre

-un hombre de verdad-

Como exes un hombre,

Son los sexes celestes

que te han engendrado.

Con el tiempo cambio esa inscripcion y se coloco la siguiente:

Aqui yace Moisés Maimonides,

el heretico desterrado.

Y el pueblo generoso, a su sabio venerado, le puso la siguiente leyenda:

De moisés a Moisés

No hubo otro Moisés igual.

El fervor de su época lo recoge la literatura:

"Oh principe de ti 
desciende nuestra gloria

de $t i$ viene

nuestra salud.

Tu, el enviado de Dios

fue formado a su imagen $y$ semejanza

Cuando te recordamos

comprendemos que a causa de

ti, Dios ha dicho.

"Crearé al hombre a mi imagen".

$Y$ en otro lugar refiriéndose a sus habilidades de médlco se dice:

El arte de Galeno

cura solo el cuerpo

El de Maimónides

el cuerpo y el espiritu

Su ciencia hizo la mejicina

del slglo

su sabidurla cura

la ausencia de sabiduria. 